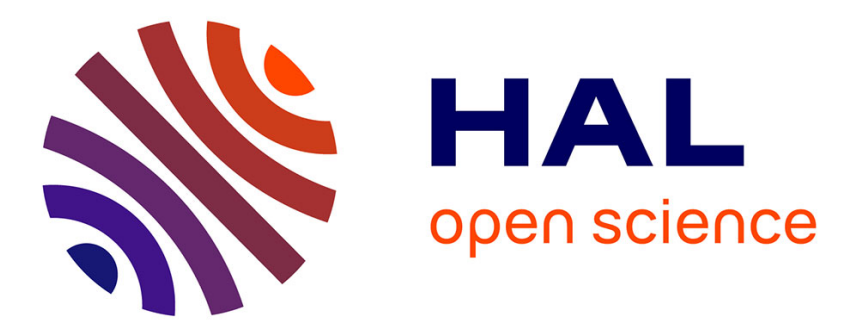

\title{
Putting Waste to Work: The Demonstrative Example of Pyrite Quarry Effluents Turned into Green Oxidative Catalysts
}

\author{
Camille Bihanic, Andrii Stanovych, Franck Pélissier, Claude Grison
}

\section{To cite this version:}

Camille Bihanic, Andrii Stanovych, Franck Pélissier, Claude Grison. Putting Waste to Work: The Demonstrative Example of Pyrite Quarry Effluents Turned into Green Oxidative Catalysts. ACS Sustainable Chemistry \& Engineering, 2019, 7 (6), pp.6223-6233. 10.1021/acssuschemeng.8b06582 . hal-02390367

\section{HAL Id: hal-02390367 https://hal.science/hal-02390367}

Submitted on 16 Feb 2021

HAL is a multi-disciplinary open access archive for the deposit and dissemination of scientific research documents, whether they are published or not. The documents may come from teaching and research institutions in France or abroad, or from public or private research centers.
L'archive ouverte pluridisciplinaire HAL, est destinée au dépôt et à la diffusion de documents scientifiques de niveau recherche, publiés ou non, émanant des établissements d'enseignement et de recherche français ou étrangers, des laboratoires publics ou privés. 


\title{
Putting Waste to Work: The Demonstrative Example of Pyrite Quarry Effluents Turned into Green Oxidative Catalysts
}

\author{
Camille Bihanic, Andrii Stanovych, Franck Pelissier, and Claude Grison*(0) \\ Laboratory of Bio-Inspired Chemistry and Ecological Innovations, UMR 5021 CNRS - University of Montpellier - ChimEco - \\ Cap Delta, 1682 Rue de la Valsière, 34790 Grabels, France
}

\begin{abstract}
In the context of exponentially growing problems of pollution and waste, the design of ecofriendly processes for turning the current treatment of effluents into sustainable catalysts represents a great opportunity. Wastewater arising from pyrite quarrying is selected as a model example. The acidity of pyrite effluents leads to solubilization of useful cations: $\mathrm{Mn}^{\mathrm{II}}$ and $\mathrm{Fe}^{\mathrm{II}} / \mathrm{Fe}^{\mathrm{III}}$. Their chemical properties are an opportunity to promote innovative studies of oxidation in organic synthesis.

The controlled addition of $\mathrm{NaOH}$ and a co-oxidant $\left(\mathrm{H}_{2} \mathrm{O}_{2}\right)$ onto the effluents allows generation of new, oxidative catalysts. MP-AES analysis, XPS, XRPD, BET, TEM,

HRTEM, and EDX studies were performed to characterize the new and efficient catalysts. Oxidation of alcohols into carbonyl compounds, oxidative cleavage of 1,2diols, and epoxidation of alkenes are described.
\end{abstract}

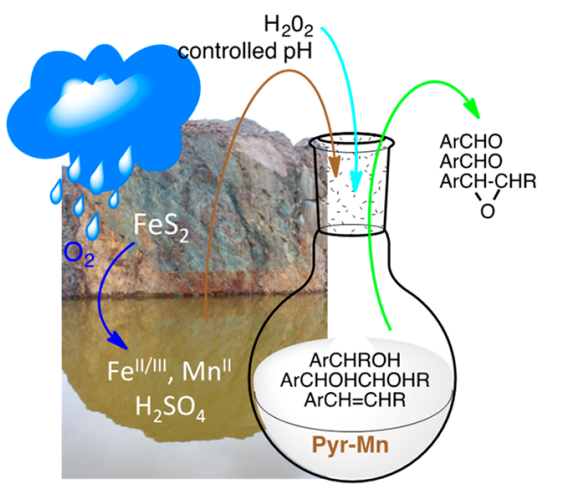

KEYWORDS: Pyrite quarrying, Turning wastes into catalysts, Sustainable oxidative catalysts, Green oxidative cleavage, Green epoxidation

\section{INTRODUCTION}

Intensive mining, quarrying, and industrial activities are causing serious dissemination of "Trace metallic Elements" (or "TEs") throughout the environment. This is an alarming problem because TEs are among the most harmful pollutants, as they are not biodegradable. ${ }^{1}$ Beyond the environmental consequences, the health risks are real: damage to the nervous and renal systems, as well as to lung and bone tissues, has been proven. Metals are transported either as dissolved species in water or as suspended sediments through rivers and streams. They accumulate in river bed sediments or seep into the groundwater, thereby contaminating underground sources. Problems related to protecting drinking water and groundwater flux are becoming a major priority.

For example, pyrite quarrying exposes sulfide and disulfide minerals to air and water, facilitating a natural chemical reaction producing sulfuric acid. This reaction increases acidity in water (often to $\mathrm{pH}$ as low as 2 or 3 ), thus rendering water quality unacceptable. The oxidation of pyrite (iron disulfide) produces sulfuric acid, but also $\mathrm{FeSO}_{4}$ and $\mathrm{MnSO}_{4}$. Under low $\mathrm{pH}$ conditions, ferrous sulfate may be oxidized into ferric sulfate (Figure 1).

Currently, the quality of effluents before discharge must meet European Performance Standards. The solutions implemented are often unsatisfactory. Managers of quarries and mines have to treat more than $200000 \mathrm{~m}^{3}$ of effluents per quarry and per year with soda or lime in order to comply with discharge standards. This costly, inadequate treatment produces new waste in the form of an alkaline sludge rich in

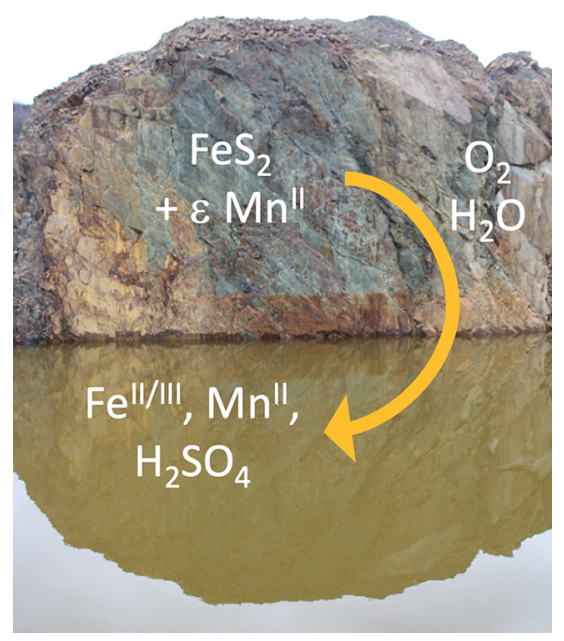

Figure 1. Formation of pyrite quarry effluents.

metal hydroxides. In the end, the problem remains unresolved. A similar situation is observed with effluents from chemical plants. Today, a major challenge is to innovate and find ecoresponsible and sustainable solutions.

In a context of exponentially growing problems of pollution and waste, the design of ecofriendly processes for transforming 
contaminated wastes into new catalysts and reagents is a powerful opportunity. Herein, we propose ways to turn the current treatment of effluents into bioinspired promoters of oxidation (Figure 2).

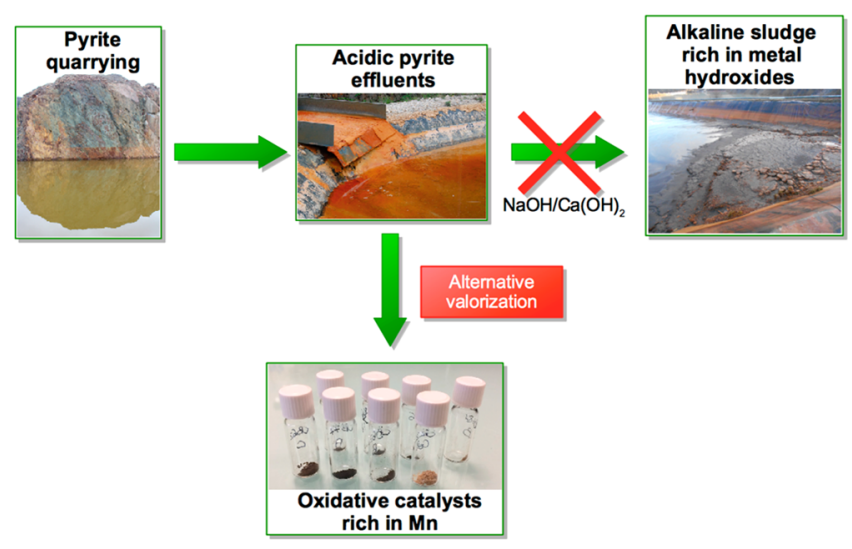

Figure 2. Transformation of pyrite quarry effluents into new oxidative catalysts as an alternative of current processes.

The acidity of effluents from pyrite quarries allows solubilization of catalytically efficient cations: $\mathrm{Mn}^{\mathrm{II}}$ and $\mathrm{Fe}^{\mathrm{II}}$ / $\mathrm{Fe}^{\mathrm{III}}$. Their natural properties are an opportunity to promote innovative oxidation processes according to three strategies using the specific chemical composition of quarrying effluents: (1) studying the conditions of alcohol oxidation into carbonyl compounds by manganese-based catalysts; (2) testing these catalysts as promoters of oxidative cleavages; and (3) carrying out experimental studies on the use of effluents for the epoxidation of alkenes. The polymetallic composition and the activity, selectivity, and recyclability of novel catalysts will be showcased in selected reactions, such as reactions traditionally employing oxidants prohibited by REACH regulations ${ }^{2}$ and the synthesis of monomers from terpenes. The key benefits of the proposed system are the recovery of problematic wastes, namely, the effluents from pyrite quarries, the possibility of recycling and reuse of these wastes, the efficiency of the system in terms of yield, the wide range of its applications, the ease of control of the reaction outcome, and the mild and ecofriendly reaction conditions.

\section{EXPERIMENTAL SECTION}

Chemicals. Reagents and solvents were purchased from SigmaAldrich and were used without further purification.

Preparation of Pyr-Mn. Hydrogen peroxide solution (30\% w/w in $\mathrm{H}_{2} \mathrm{O}$ ) was added to effluents from the Pleyber-Christ mining site (France, Table 1), and the solution was stirred at room temperature. After $30 \mathrm{~min}, \mathrm{NaOH}(2 \mathrm{M})$ was added drop-by-drop until the desired $\mathrm{pH}$ was reached. A precipitate formed. The solution was let under stirring at room temperature for $12 \mathrm{~h}$. The solid was then recovered by filtration and washed with deionized water (3 times) and then with absolute ethanol ( 3 times). The resulting solid was dried in an oven at $140{ }^{\circ} \mathrm{C}$ for $24 \mathrm{~h}$.

Preparation of Synthetic Mn Catalyst. Manganese sulfate monohydrate $(972 \mu \mathrm{mol})$ was put in ultrapure water $(1 \mathrm{~L})$. Hydrogen peroxide solution $\left(30 \% \mathrm{w} / \mathrm{w}\right.$ in $\mathrm{H}_{2} \mathrm{O}$ ) was added, and the solution was stirred at room temperature. After $30 \mathrm{~min}, \mathrm{NaOH}(2 \mathrm{M})$ was added drop-by-drop until the $\mathrm{pH}$ reached 11. A precipitate formed. The solution was let under stirring at room temperature for $12 \mathrm{~h}$. The solid was then recovered by filtration and washed with deionized water ( 3 times) and then with absolute ethanol (3 times). The resulting solid was dried in an oven at $140{ }^{\circ} \mathrm{C}$ for $24 \mathrm{~h}$.

Preparation of Synthetic Mn-Ca Catalyst. Manganese sulfate monohydrate $(243 \mu \mathrm{mol})$ and calcium sulfate $(211 \mu \mathrm{mol})$ were put in ultrapure water $(1 \mathrm{~L})$. Hydrogen peroxide solution $(30 \% \mathrm{w} / \mathrm{w}$ in $\mathrm{H}_{2} \mathrm{O}$ ) was added, and the solution was stirred at room temperature. After $30 \mathrm{~min}, \mathrm{NaOH}(2 \mathrm{M})$ was added drop-by-drop until the $\mathrm{pH}$ reached 11. A precipitate formed. The solution was let under stirring at room temperature for $12 \mathrm{~h}$. The solid was then recovered by filtration and washed with deionized water (3 times) then with absolute ethanol ( 3 times). The resulting solid was dried in an oven at $140{ }^{\circ} \mathrm{C}$ for $24 \mathrm{~h}$.

Preparation of Synthetic Mn-Mg Catalyst. Manganese sulfate monohydrate $(243 \mu \mathrm{mol})$ and magnesium sulfate $(270 \mu \mathrm{mol})$ were put in ultra pure water $(1 \mathrm{~L})$. Hydrogen peroxide solution $(30 \% \mathrm{w} / \mathrm{w}$ in $\mathrm{H}_{2} \mathrm{O}$ ) was added and the solution was stirred at room temperature. After $30 \mathrm{~min}, \mathrm{NaOH}(2 \mathrm{M})$ was added drop-by-drop until $\mathrm{pH}$ reached 11. A precipitate formed. The solution was let under stirring at room temperature for $12 \mathrm{~h}$. The solid was then recovered by filtration and washed with deionized water ( 3 times) then with absolute ethanol ( 3 times). The resulting solid was dried in an oven at $140{ }^{\circ} \mathrm{C}$ for $24 \mathrm{~h}$.

Preparation of Synthetic $\mathbf{M n}-\mathbf{C a}-\mathbf{M g}$ Catalyst. Manganese sulfate monohydrate $(243 \mu \mathrm{mol})$, calcium sulfate $(211 \mu \mathrm{mol})$ and magnesium sulfate $(270 \mu \mathrm{mol})$ were put in ultra pure water $(1 \mathrm{~L})$. Hydrogen peroxide solution $\left(30 \% \mathrm{w} / \mathrm{w}\right.$ in $\left.\mathrm{H}_{2} \mathrm{O}\right)$ was added and the solution was stirred at room temperature. After $30 \mathrm{~min}, \mathrm{NaOH}(2 \mathrm{M})$ was added drop-by-drop until $\mathrm{pH}$ reached 11 . A precipitate formed. The solution was let under stirring at room temperature for $12 \mathrm{~h}$. The solid was then recovered by filtration and washed with deionized water ( 3 times) and then with absolute ethanol (3 times). The resulting solid was dried in an oven at $140{ }^{\circ} \mathrm{C}$ for $24 \mathrm{~h}$.

Characterization of the Catalysts. Mineral composition of the catalysts was determined using an Agilent 4200 microwave plasmaatomic emission spectrometer (MP-AES) coupled with a SPS4 autosampler. The samples were digested in $6 \mathrm{~mL}$ of reversed aqua regia $(1: 2$ hydrochloric acid $(37 \%) /$ nitric acid $(65 \%))$ under an Anton Paar Multiwave Go microwave-assisted digestion, with the following program: $20-164{ }^{\circ} \mathrm{C}$ in $20 \mathrm{~min}$ then $10 \mathrm{~min}$ isothermal at $164{ }^{\circ} \mathrm{C}$. Samples were filtered and then diluted to $0.2 \mathrm{~g} \mathrm{~L}^{-1}$ in nitric acid (1\%). Three blanks were recorded for each step of the dilution procedure. Three analyses were carried out for each sample in order to determine the standard deviation of the measurement.

The specific surface area and pore size distribution of the catalysts were inferred from the measurements of adsorption-desorption of gaseous nitrogen at $77 \mathrm{~K}$ with the use of a Micromeritics Tristar unit. Prior to the experiment, each sample was degassed down to $2 \mathrm{~Pa}$ at $120{ }^{\circ} \mathrm{C}$ for $12 \mathrm{~h}$.

X-ray powder diffraction (XRPD) data measurements on the samples dried at $100{ }^{\circ} \mathrm{C}$ for $2 \mathrm{~h}$ were provided by using a BRUKER

Table 1. Study of Mineral Composition of Different Effluents Derived from Pyrite Quarrying According to the Seasons

\begin{tabular}{cccccccc} 
& \multicolumn{5}{c}{ composition (ppm) } \\
\cline { 2 - 7 } effluent & $\mathrm{Mn}$ & $\mathrm{Na}$ & $\mathrm{K}$ & $\mathrm{Mg}$ & $\mathrm{Ca}$ & $\mathrm{Fe}$ & $\mathrm{Al}$ \\
effluent 1 $(2016 / 12)$ & $13.4( \pm 0.1)$ & $31.8( \pm 0.5)$ & $6.6( \pm 0.1)$ & $63.2( \pm 0.3)$ & $71.4( \pm 0.9)$ & $5.1( \pm 0.1)$ & $5.2( \pm 0.1)$ \\
effluent 2 $(2016 / 12)$ & $12.3( \pm 0.1)$ & $31.8( \pm 0.3)$ & $6.3( \pm 0.04)$ & $58.2( \pm 0.4)$ & $65.3( \pm 1.0)$ & $1.8( \pm 0.02)$ & $4.3( \pm 0.04)$ \\
effluent 3 $(2017 / 05)$ & $9.1( \pm 0.03)$ & $26.4( \pm 0.1)$ & $5.3( \pm 0.1)$ & $36.9( \pm 0.2)$ & $55.2( \pm 1.1)$ & $2.2( \pm 0.03)$ & $3.0( \pm 0.02)$ \\
effluent 4 (2017/11) & $11.4( \pm 0.2)$ & $33.0( \pm 0.7)$ & $5.3( \pm 0.1)$ & $50.5( \pm 0.7)$ & $80.2( \pm 1.9)$ & $7.2( \pm 0.2)$ & $4.2( \pm 0.03)$
\end{tabular}


Table 2. Mineral Composition of the Catalysts Synthesized at Different $\mathrm{pH}$ of Precipitation

\begin{tabular}{|c|c|c|c|c|c|c|c|}
\hline \multirow[b]{2}{*}{$\mathrm{pH}$ of precipitation } & \multicolumn{7}{|c|}{ composition $($ wt $\% \pm \mathrm{SD})$} \\
\hline & $\mathrm{Mn}$ & $\mathrm{Na}$ & $\mathrm{K}$ & $\mathrm{Mg}$ & $\mathrm{Ca}$ & $\mathrm{Fe}$ & $\mathrm{Al}$ \\
\hline $9.5\left(\right.$ Pyr- $\left.-\mathrm{Mn}_{1}\right)$ & $12.6( \pm 1.1)$ & $0.1( \pm 0.04)$ & $0.1( \pm 0.1)$ & $2.7( \pm 0.3)$ & $2.1( \pm 0.2)$ & $4.8( \pm 1.3)$ & $4.3( \pm 0.4)$ \\
\hline $11\left(\right.$ Pyr-Mn $\left.{ }_{2}\right)$ & $3.5( \pm 0.6)$ & $0.1( \pm 0.04)$ & $0.1( \pm 0.04)$ & $13.0( \pm 1.5)$ & $6.3( \pm 2.2)$ & $1.6( \pm 0.8)$ & $1.2( \pm 0.1)$ \\
\hline $14\left(\operatorname{Pyr}-\mathrm{Mn}_{3}\right)$ & $2.8( \pm 0.1)$ & 0.0 & 0.0 & $13.2( \pm 0.2)$ & $14.4( \pm 0.5)$ & $0.3( \pm 0.1)$ & $1.0( \pm 0.1)$ \\
\hline
\end{tabular}

diffractometer (D8 Advance, with $\mathrm{Cu} \mathrm{K} \alpha$ radiation at $1.54086 \AA$ ) equipped with a Lynxeyes detector.

$\mathrm{X}$-ray photoelectron spectroscopy (XPS) analyses were carried out with an ESCALAB $250 \mathrm{X}$-ray photoelectron spectrometer from Thermo Electron. The spectra were generated by $\mathrm{Al} \mathrm{K} \alpha \mathrm{X}$-ray at $1486.6 \mathrm{eV}$. The surface of the sample that was analyzed had a diameter of $400 \mu \mathrm{m}$. All the binding energies were referenced to the $\mathrm{C}$ 1s core-level energy at $284.8 \mathrm{eV}$.

Transmission electron microscopy (TEM) images were taken using a JEOL 1200EX2 transmission electron microscope at an accelerating voltage of $100 \mathrm{kV}$, equipped with a CCD EMSIS Olympus $11 \mathrm{Mpx}$ Quemesa CCD at the MEA platform (University of Montpellier, France). In each case, ecocatalysts were grounded into a thin powder and put in suspension in ethanol. Each suspension of catalyst was dropped on a carbon coated copper grid (300 mesh).

High resolution transmission electron microscopy (HRTEM) analyses were performed at $200 \mathrm{kV}$ on a JEOL 2200 FS equipped with a CCD Gatan Ultrascan 4000 CCD $\left(4092 \times 4092 \mathrm{px}^{2}\right)$ at the MEA platform (University of Montpellier, France). Scanning transmission electron microscopy-energy dispersive $\mathrm{x}$-ray spectroscopy (STEM-EDX) was used to obtain chemical mapping, with a probe size of $0.7 \mathrm{~nm}$. The EDS spectra were recorded on a Silicon Drift X-MAX ${ }^{\mathrm{n}}$ 100TLE detector from Oxford Instrument. Sample were embedded in LR White resin and cut (thin section of $70 \mathrm{~nm}$ ) with a Leica UC7 ultramicrotome equipped with a Diatome diamond. Sections were deposited on carbon coated copper grid (300 mesh).

Benzyl Alcohol Oxidation. In a typical procedure, benzyl alcohol $(1 \mathrm{mmol})$, catalyst $(0.3$ equiv $\mathrm{Mn})$, and anhydrous toluene $(10 \mathrm{~mL})$ were added to a three-neck flask with a magnetic stirring bar. The reaction mixture was stirred under reflux at $110^{\circ} \mathrm{C}$ with air flow for 5 h. The catalyst was then filtered and washed with ethyl acetate (3 times) and ethanol ( 3 times) before being dried in an oven at $140{ }^{\circ} \mathrm{C}$ for $24 \mathrm{~h}$.

Oxidative Cleavage of 1,2-Diols. In a typical procedure, 1,2-diol $(0.5 \mathrm{mmol})$, catalyst $(0.3$ equiv $\mathrm{Mn})$, and anhydrous toluene $(5 \mathrm{~mL})$ were added to a three-neck flask with a magnetic stirring bar. The reaction mixture was stirred under reflux at $110^{\circ} \mathrm{C}$ with air flow for 5 h. The catalyst was then filtered and washed with ethyl acetate (3 times) and ethanol ( 3 times) before being dried in an oven at $140{ }^{\circ} \mathrm{C}$ for $24 \mathrm{~h}$.

Epoxidation of Alkenes. In a typical procedure, the effluent ( 0.00006 equiv $\mathrm{Mn}), \mathrm{NaHCO}_{3}(0.88 \mathrm{mmol})$, and alkene $(0.18 \mathrm{mmol})$ were stirred in $t-\mathrm{BuOH}$ or acetone $(2.6 \mathrm{~mL})$ at room temperature for $10 \mathrm{~min} . \mathrm{H}_{2} \mathrm{O}_{2}\left(30 \% \mathrm{w} / \mathrm{w}\right.$ in $\left.\mathrm{H}_{2} \mathrm{O}, 1.75 \mathrm{mmol}\right)$ was added and the mixture was stirred during $2 \mathrm{~h}$ at $30{ }^{\circ} \mathrm{C}$.

Analyses of Reaction Products. Gas chromatography-mass spectroscopy (GC-MS) analyses were performed on a Thermo Scientific Trace 1300 GC coupled with an ISQ QD quadrupole and a Thermo TG-5SILMS column $(0.18 \mu \mathrm{m} \times 0.18 \mu \mathrm{m} \times 20 \mathrm{~mm})$ with hydrogen as carrier gas $\left(1 \mathrm{~mL} \mathrm{~min}^{-1}\right)$. The program followed was: 30 $\mathrm{s}$ isothermal at $80{ }^{\circ} \mathrm{C}, 80{ }^{\circ} \mathrm{C}-280{ }^{\circ} \mathrm{C}$ at $40{ }^{\circ} \mathrm{C} \mathrm{min}^{-1}$ then $30 \mathrm{~s}$ isothermal at $280^{\circ} \mathrm{C}$. Conversion and selectivity were established by GC-MS, using dodecane or biphenyl as intern standard. Mass spectra were recorded in impact electronic mode at $70 \mathrm{~V}$, and identification was made by using the NIST 14 database.

Fourier transform infrared spectroscopy (FTIR) spectra were recorded using a PerkinElmer Spectrum100 FT-IR spectrometer, between 1400 and $1600 \mathrm{~cm}^{-1}$.

\section{RESULTS AND DISCUSSION}

A feature of effluents from pyrite quarrying was the variation in their chemical composition, which depends on climatic conditions and the natural composition of rock. We studied the composition of a model quarrying site, Pleyber-Christ in France, during different seasons (autumn and summer). The MP-AES was used to determine the exact chemical composition of effluents (Table 1). As expected, autumnal effluents were more concentrated than summer ones, as the result of seasonal precipitation leaching. However, whichever season, the mineral composition of effluents followed the same trend: the analysis clearly revealed that $\mathrm{Mn}$ was the major transition metal (9-13\%), accompanied by an amount of $1-$ $7 \% \mathrm{Fe}$. An amount of $3-5 \% \mathrm{Al}$ was also noted. Whereas the content of cations ( $\mathrm{Al}, \mathrm{Na}, \mathrm{K}$ ) was stable in the samples, significant differences were observed for $\mathrm{Mn}, \mathrm{Fe}, \mathrm{Mg}$, and $\mathrm{Ca}$. Transition metals present in effluents are an intended source of oxidation activity, but a difference in $\mathrm{Mg}$ and $\mathrm{Ca}$ content could modulate the catalytic activity by some synergetic effects. Indeed, a cooperative effect between $\mathrm{Mn}$ and $\mathrm{Ca}$ for oxidation is possible. The cofactor $\left(\mathrm{Mn}_{4} \mathrm{CaO}_{5}\right)$ in photosystem II, which is able to oxidize $\mathrm{H}_{2} \mathrm{O}$, is a demonstrative natural example. ${ }^{3} \mathrm{On}$ the contrary, $\mathrm{Mg}$ is known to show an antagonist effect on the Mn oxidizing property. ${ }^{4}$ Therefore, it was interesting to study the synthetic potential of this polymetallic composition as sustainable catalytic alternatives in oxidation reactions.

Studying the Conditions of Alcohol Oxidation into Carbonyl Compounds. The selective oxidation of alcohols into carbonyl compounds needs new green catalytic alternatives. The catalytic oxidation with $\mathrm{H}_{2} \mathrm{O}_{2}$ is widely used, because it presents numerous advantages: it is considered to be clean and cheap, is an excellent oxygen donor, and does not generate waste or coproduct. ${ }^{5}$ Among the transition elements known to catalyze oxygen transfer process, $\mathrm{Mn}$ is clearly preferred because of its low toxicity and its abundance in the Earth's crust. ${ }^{6,7}$

Oxidations by $\mathrm{Mn}^{\mathrm{IV}}$ are usually soft and selective. Their chemoselectivity is interesting; for example, there is no oxidation of phenol and no overoxidation of benzylic aldehydes. ${ }^{8} \mathrm{MnO}_{2}$ is considered as a potential green oxidant. It is not soluble in either organic solvents or water, and thus, it is recyclable via filtration, with very low dispersion into the environment and low toxicity. However, there are drawbacks to the standard system: $\mathrm{MnO}_{2}$ needs to be activated (chemical treatments, use of $\mathrm{KMnO}_{4}$ ). Additionally, high excess (10-15 equiv) and long reaction times are necessary. The development of catalytic methodology for soft oxidation by $\mathrm{Mn}^{\mathrm{IV}}$ was motivating. Our recent reports using catalysts prepared from Mn-rich plant extracts, ${ }^{9-12}$ called Eco-Mn and Eco-MnOx, revealed an unique polymetallic composition and displayed superior catalytic performances than conventional Mn catalysts in oxidative transformations. These results prompted us to investigate the preparation of novel $\mathrm{Mn}$-rich polymetallic systems by the controlled addition of $\mathrm{NaOH}$ and co-oxidant 
$\left(\mathrm{O}_{2}\right.$ or $\left.\mathrm{H}_{2} \mathrm{O}_{2}\right)$ onto the effluent, to generate new materials, called Pyr-Mn.

To ensure an optimal preparation of efficient catalysts, the best conditions for precipitation of useful species as a function of $\mathrm{pH}$ had to be taken into account. The catalysts synthesis followed the same steps as for the synthesis of already reported Eco-MnOx ${ }^{12}$ but using effluents as manganese source. Pyr-Mn were prepared by oxidation of the elements present in effluents by $\mathrm{H}_{2} \mathrm{O}_{2}$ and subsequently precipitated by addition of $\mathrm{NaOH}$. The precipitate was collected by filtration. Analysis of the mineral composition of the catalysts synthesized at different $\mathrm{pH}$ was provided by MP-AES (Table 2).

As expected, by using solubility product constants of the different metallic hydroxides, ${ }^{13}$ the maximal percentage of $\mathrm{Fe}$ and $\mathrm{Mn}$ was obtained at $\mathrm{pH} 9.5$ (Table 2, Figure S1). It should be noted that the ratio $\mathrm{Mn} / \mathrm{Ca}$ was close to the one of $\mathrm{Mn}_{4} \mathrm{CaO}_{5}$, the cofactor of photosystem II. At $\mathrm{pH} 11, \mathrm{Mg}$ became the major element, whereas at $\mathrm{pH} 14 \mathrm{Mg}$ and $\mathrm{Ca}$ represented the most abundant species. In the two latter cases, $\mathrm{Mn}$ was dispersed in a mineral matrix of alkaline earth metal cations. The substantial amount of $\mathrm{Al}$ can be of special importance as mixed $\mathrm{Mn} / \mathrm{Al}$ catalysts have shown oxidizing properties. $^{14}$

High chemodiversity of metal elements, such as Fe, Mn, Ca, and $\mathrm{Al}$, is an opportunity to create synergistic effects for green oxidations. Studying the morphology, microstructure, and properties of these novel catalysts Pyr-Mn was required to understand and control interactions between metals and reagents for innovation in oxidative synthesis. We focused on Pyr- $\mathrm{Mn}_{1}$ and Pyr- $\mathrm{Mn}_{2}$, as Pyr- $\mathrm{Mn}_{3}$ showed very poor reactivity in benzylic alcohol oxidation, taken as our first model reaction (Table 4, entries 5 and 6).

Catalysts Characterization. The specific surface area $S_{\mathrm{BET}}$ of Pyr-Mn was determined by the Brunauer-Emmett-Teller method (BET). The specific surface area of Pyr-Mn catalysts obtained at $\mathrm{pH} 9.5$ and 11 were compared to commercial activated $\mathrm{MnO}_{2}$ and other $\mathrm{MnO}_{2}$ catalysts with different morphologies. The data are summarized in Table 3. Pyr- $\mathrm{Mn}_{1}$ and Pyr- $\mathrm{Mn}_{2}$ exhibited high specific surface areas, with 209 and $119 \mathrm{~m}^{2} \mathrm{~g}^{-1}$, respectively. Furthermore, these values mostly exceeded those of classic $\mathrm{MnO}_{2}$ materials.

XRPD was performed to deliver insights regarding the structure of Pyr- $\mathrm{Mn}_{1}$ and $\mathrm{Pyr}-\mathrm{Mn}_{2}$. Only one component was detected: calcium sulfate, originally present in effluents. Manganese oxide was not present in a crystalline form,

Table 3. Specific Surface Area of Pyr-Mn Catalysts, Commercial Activated $\mathrm{MnO}_{2}$, and Other $\mathrm{MnO}_{2}$ Catalysts

\begin{tabular}{|c|c|c|}
\hline catalyst & refs & $\begin{array}{l}S \text { surface area } \\
\left(\mathrm{m}^{2} \mathrm{~g}^{-1}\right)\end{array}$ \\
\hline Pyr-Mn 1 & $\mathrm{pH} 9.5$ [this article] & 209 \\
\hline Pyr-Mn 2 & $\mathrm{pH} 11$ [this article] & 119 \\
\hline commercial activated $\mathrm{MnO}_{2}$ & [this article] & 88 \\
\hline $\mathrm{Mn}_{0.74} \mathrm{Cu}_{0.01} \mathrm{Al}_{0.25}$ & 14 & $75-115$ \\
\hline amorphous $\mathrm{MnO}_{2}$ & 15 & 189 \\
\hline $\begin{array}{l}\text { birnessite-type } \mathrm{MnO}_{2}(\mathrm{Na}- \\
\text { OL-1) }\end{array}$ & 15 & 57 \\
\hline$\gamma-\mathrm{MnO}_{2}$ & 15 & 38 \\
\hline OMS-1 & 15 & 47 \\
\hline OMS-2 & 15 & 81 \\
\hline OMS-6 & 15 & 53 \\
\hline OMS-7 & 15 & 17 \\
\hline
\end{tabular}

which is consistent with the structure of active manganese dioxide. $^{8}$

In order to check the valence state of $\mathrm{Mn}$ ions in near surface areas, XPS was performed. Pyr- $\mathrm{Mn}_{1}$ and $\mathrm{Pyr}-\mathrm{Mn}_{2}$ exhibited similar XPS spectra. In the Mn $2 p$ spectra, peaks at 642.4 and $654.4 \mathrm{eV}$ corresponded to the spin orbit doublet of Mn $2 \mathrm{p}_{3 / 2}$ and $\mathrm{Mn} 2 \mathrm{p}_{1 / 2}$ respectively (Figure S2). Mn $2 \mathrm{p}_{3 / 2}$ binding energy seemed to correspond to $\mathrm{Mn}^{\mathrm{IV}}$ present in $\mathrm{MnO}_{2}{ }^{96,17}$

Nevertheless, a clear distinction between $\mathrm{Mn}^{\mathrm{III}}$ and $\mathrm{Mn}^{\mathrm{IV}}$ oxidation states is difficult by using $\mathrm{Mn} 2 \mathrm{p}_{3 / 2}$ photopeak position, especially in the case of a combination of different oxidation state species, which would result in overlapping $\mathrm{Mn}$ $2 p$ peaks. Hence, in the present case, a great number of simple and mixed stoichiometric manganese oxides was not to exclude. A deconvolution of Mn $2 p$ spectra into several subbands, using LabSpec5 and fitting parameters from Biesinger et al., ${ }^{18}$ was carried out. However, the poor resolution of the spectra made it difficult to draw any reliable conclusions. The absence of a satellite peak at $647.4 \mathrm{eV}$, characteristic for $\mathrm{Mn}^{\mathrm{II}}$, confirmed that $\mathrm{MnO}$ was not present in the catalysts. ${ }^{19}$

To overcome this problem, multiplet splitting of Mn 3s photopeak is widely used as a more accurate approach to distinguish the two oxidation states or to estimate their ratios in mixed oxides. Unfortunately, Mn 3s spectra could not give more information because of the interference with $\mathrm{Mg}$ peak.

Significant differences concerning Pyr-Mn catalysts and commercial activated $\mathrm{MnO}_{2}$, used as the reference system, led us to study the morphology of these materials by using TEM, HRTEM, and EDX performed by using STEM.

TEM images revealed thin lamellar particles aggregated into crumpled-tissue-paper structures of about 100-200 nm diameter, for both Pyr- $\mathrm{Mn}_{1}$ and $\mathrm{Pyr}-\mathrm{Mn}_{2}$ (Figure 3). These

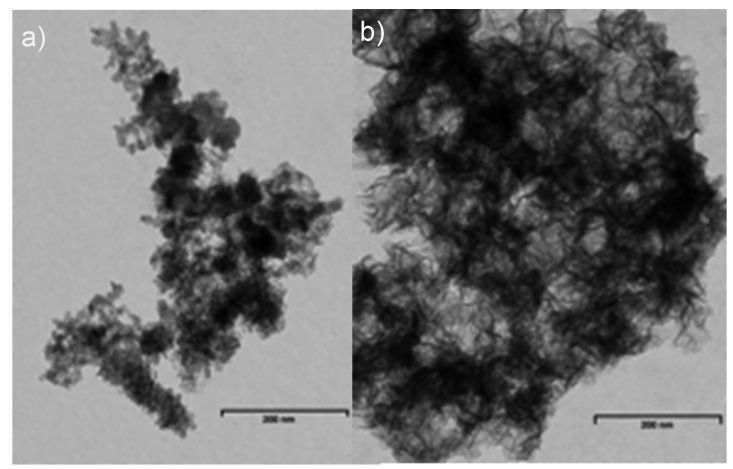

Figure 3. TEM images of (a) Pyr- $\mathrm{Mn}_{1}$ and (b) $\mathrm{Pyr}-\mathrm{Mn}_{2}$.

particles looked more uniformly aggregated for Pyr- $\mathrm{Mn}_{2}$ than for Pyr- $\mathrm{Mn}_{1}$, even if no clear organization was visible in both cases, confirming the results of XRPD. This type of arrangement is in accordance with different types of conventional $\mathrm{MnO}_{2}$ structures. ${ }^{20-22}$ Commercial activated $\mathrm{MnO}_{2}$ exhibited a totally different structure with rodlike particles of about $10-30 \mathrm{~nm}$ width over 50-100 nm length (Figure S3). HRTEM images did not only confirm these structures but also support the results obtained by $\mathrm{N}_{2}$ adsorption-desorption measurements. Indeed, Pyr- $\mathrm{Mn}_{1}$ and $\mathrm{Pyr}-\mathrm{Mn}_{2}$ showed type IV isotherms with a $\mathrm{H} 3$ hysteresis, confirming a nonrigid aggregates of plate-like particles with slit-shaped pores (Figure $\mathrm{S} 4 \mathrm{a}$ and $\mathrm{b}$ ). Pore diameters were estimated using the BarrettJoyner-Halenda (BJH) method from the desorption branch of 
the nitrogen isotherm. Following similar results obtained by Augustin et al. ${ }^{23}$ for the isotherms, the "pores" detected could correspond to the space between particles in the network. This assumption is in good agreement with the broad pore size distributions obtained for Pyr- $\mathrm{Mn}_{1}$ and $\mathrm{Pyr}-\mathrm{Mn}_{2}$, ranging from $3 \mathrm{~nm}$ to more than $500 \mathrm{~nm}$ (Figure S4a and b). For commercial activated $\mathrm{MnO}_{2}$, the pore size distribution from 3 to $20 \mathrm{~nm}$ and from 29 to $37 \mathrm{~nm}$ could be explained in the same way (Figure S4c). It should be noticed that the spike in the $\mathrm{N}_{2}$ desorption pore size distribution of $\mathrm{Pyr}-\mathrm{Mn}_{2}$, not appearing in the adsorption pore size distribution, reflected an artifact (Figure S4b). This artifact is caused by a spontaneous evaporation of the capillary condensate, phenomena which can occur, for instance, for ink-bottleneck type cavities.

STEM-EDX mapping was used to establish chemical composition mapping of our catalysts. The different elemental distributions gave some useful information on the overall composition. The presence of manganese, iron, calcium, magnesium and aluminum was in accordance with MP-AES analysis. Sulfide certainly stemmed from sulfate from pyrite effluents and supported XRPD analysis. In each case, the manganese and oxygen maps were overlaid, confirming the formation of some manganese oxides (Figures 4 and S5). Otherwise, STEM-EDX mapping results showed an aggregation of all elements in the particles, where manganese and oxygen were concentrated. This information is of the utmost importance, as it supports the polymetallic structure of the catalysts.

Catalyst Performance Evaluation through the Aerobic Oxidation of Alcohols. The aerobic oxidation of benzyl alcohol into benzaldehyde was chosen as model reaction to design the best reaction conditions. Oxygen from air was used as co-oxidant to regenerate the catalysts. In stoichiometric quantities, high yields were obtained with $\mathrm{Pyr}-\mathrm{Mn}_{1}$ (Table 4, entry 1). No retention of the reagents and products onto the catalyst mineral matrix was observed unlike for $\mathrm{Pyr}-\mathrm{Mn}_{2}$ and Pyr- $\mathrm{Mn}_{3}$ (Table 4, entries 3 and 5). However, when Pyr- $\mathrm{Mn}_{1}$ and $\mathrm{Pyr}-\mathrm{Mn}_{3}$ were involved in catalytic quantity, the conversion was poor, even under air flow (Table 4, entries 2 and 6). On the contrary, at $\mathrm{pH} 11,79 \%$ conversion was obtained with only 0.3 equiv Mn (Table 4, entry 4). In all cases, complete selectivity toward benzaldehyde was obtained, without any overoxidation to benzoic acid.

To better understand the reactivity of the catalysts, and the synergetic/antagonist effects of other elements present in the polymetallic structures (mostly calcium and magnesium), synthetic catalysts were prepared from manganese, calcium and/or magnesium salts. The oxidation reaction of benzyl alcohol was also tested with those synthetic catalysts.

Total conversion and selectivity were reached for manganese alone and manganese-calcium catalysts (Table 5, entries 2 and 3 ). These results testified the synergetic or neutral effect of calcium over the Mn oxidizing properties. As these results could not give clear evidence of calcium role, the two synthetic catalysts were engaged in the oxidation of 5-hydroxymethyl-2furfural (HMF). In this case, only $20 \%$ conversion was obtained with $\mathrm{Mn}$ synthetic catalyst against $36 \%$ conversion with Mn-Ca synthetic catalyst. This last example confirmed the synergetic role of calcium over manganese oxidizing activity. On the other hand, magnesium antagonist role was clear, as GC-MS yield dropped to $66 \%$ and $89 \%$ for $\mathrm{Mn}-\mathrm{Mg}$ and $\mathrm{Mn}-$ $\mathrm{Ca}-\mathrm{Mg}$ synthetic catalysts, respectively (Table 5, entries 4 and 5).
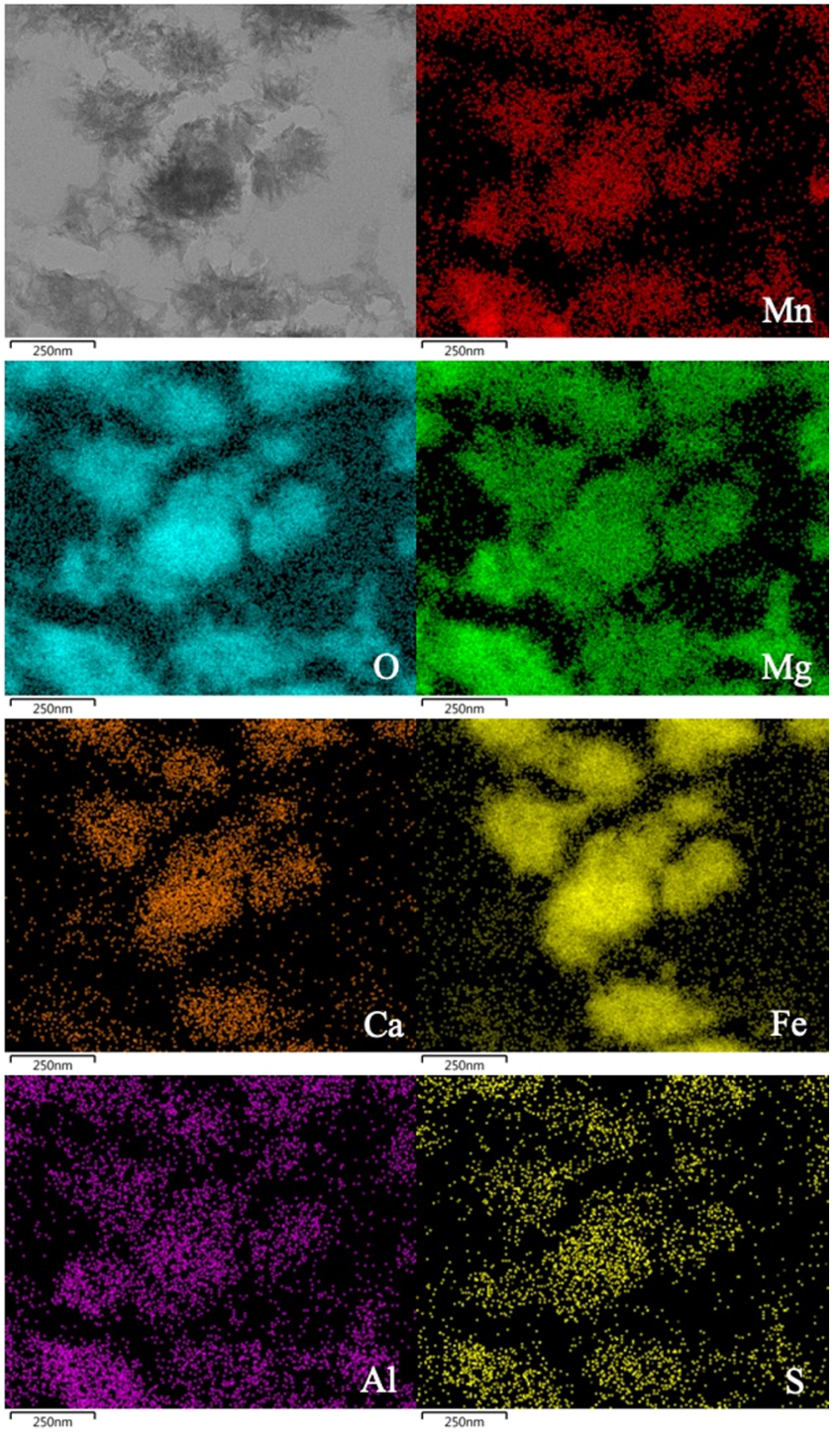

Figure 4. STEM-EDX mapping of $\mathrm{Pyr}-\mathrm{Mn}_{2}$.

Table 4. Comparison of the Activity of Different Catalysts in the Aerobic Oxidation of Benzyl Alcohol ${ }^{a}$

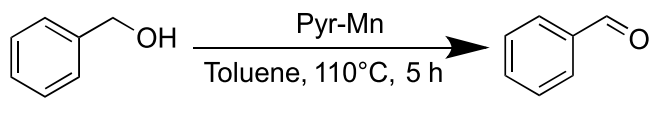

1

2

$\begin{array}{cccccc}\text { entry } & \text { catalyst } & \begin{array}{c}\text { equiv } \\ \mathrm{Mn}\end{array} & \begin{array}{c}\text { conversion } \\ {[\%]^{b}}\end{array} & \begin{array}{c}\text { yield } \\ {[\%]^{b}}\end{array} & \begin{array}{c}\text { selectivity } \\ {[\%]^{b, c}}\end{array} \\ 1 & \mathrm{Pyr}^{b} \mathrm{Mn}_{1} & 1 & 70 & 69 & >99 \\ 2^{d} & \mathrm{Pyr}^{-\mathrm{Mn}_{1}} & 0.3 & 22 & 21 & >99 \\ 3 & \mathrm{Pyr}^{-\mathrm{Mn}_{2}} & 1 & \leq 86^{e} & \geq 44^{e} & \\ 4^{d} & \mathrm{Pyr}^{\mathrm{Mnn}} & 0.3 & 79 & 78 & >99 \\ 5 & \mathrm{Pyr}_{2}-\mathrm{Mn}_{3} & 1 & \leq 45^{e} & \geq 16^{e} & \\ 6^{d} & \mathrm{Pyr}-\mathrm{Mn}_{3} & 0.3 & 10 & 9 & >99\end{array}$

${ }^{a}$ Reaction conditions: benzyl alcohol $(1 \mathrm{mmol})$, catalyst, anhydrous toluene $(10 \mathrm{~mL})$, temperature $110{ }^{\circ} \mathrm{C}, 5 \mathrm{~h} .{ }^{b}$ Conversion, yield and selectivity were established by GC-MS, using dodecane as internal standard. ${ }^{c}$ The selectivity was calculated as the ratio of yield over conversion. ${ }^{d}$ Reaction under air flow. ${ }^{e}$ Loose of reagents and products onto catalyst matrix. 
Table 5. Comparison of the Activity of Pyr- $\mathrm{Mn}_{2}$ with that of Synthetic and Commercial Catalysts in Benzyl Alcohol Oxidation

\begin{tabular}{|c|c|c|c|c|c|c|}
\hline entry & oxidative agent & equiv & $t[\mathrm{~h}]$ & solvent & conversion $[\%]^{b}$ & yield $[\%]^{b}$ \\
\hline $1^{a}$ & Pyr- $-\mathrm{Mn}_{2}$ & 0.3 & 5 & toluene & 79 & 78 \\
\hline $2^{a}$ & synthetic Mn catalyst & 0.3 & 5 & toluene & $>99$ & 99 \\
\hline $3^{a}$ & synthetic $\mathrm{Mn}-\mathrm{Ca}$ catalyst & 0.3 & 5 & toluene & $>99$ & 99 \\
\hline $4^{a}$ & synthetic $\mathrm{Mn}-\mathrm{Mg}$ catalyst & 0.3 & 5 & toluene & 67 & 66 \\
\hline $5^{a}$ & synthetic $\mathrm{Mn}-\mathrm{Ca}-\mathrm{Mg}$ catalyst & 0.3 & 5 & toluene & 90 & 89 \\
\hline $6^{a}$ & Activated $\mathrm{MnO}_{2}$ & 0.3 & 5 & toluene & 37 & 36 \\
\hline 7 & $\mathrm{MnO}_{2}^{24}$ & 12 & 23 & chloroform & & 89 \\
\hline 8 & K-OMS- $2^{30}$ & 0.5 & 4 & toluene & 90 & 89 \\
\hline 9 & Amorphous $\mathrm{MnO}_{x}^{25}$ & & 1.5 & toluene & $18-73$ & $17-72$ \\
\hline 10 & $\gamma-\mathrm{MnO}_{2}^{25}$ & 0.5 & 1.5 & toluene & 39 & 38 \\
\hline 11 & dipyridine $\mathrm{Cr}(\mathrm{IV})$ oxide $^{31}$ & 6 & 0.4 & dichloromethane & & 95 \\
\hline 12 & Dess-Martin Periodinane ${ }^{32}$ & 1 & 2 & acetonitrile & $>99$ & 99 \\
\hline 13 & DMSO- $(\mathrm{COCl})_{2}^{33}$ & 2.2 & 0.3 & dichloromethane & $>99$ & 99 \\
\hline
\end{tabular}

${ }^{a}$ Reaction conditions: benzyl alcohol $(1 \mathrm{mmol})$, catalyst $(0.3$ eq. $\mathrm{Mn})$, anhydrous toluene $(10 \mathrm{~mL})$, under air flow, temperature $110{ }^{\circ} \mathrm{C}, 5 \mathrm{~h}$. ${ }^{b}$ Conversion, yield and selectivity were established by GC-MS, using dodecane as intern standard. ${ }^{c}$ The selectivity was calculated as the ratio of yield over conversion.

Table 6. Extension of the Process to the Oxidation of Other Alcohols by Pyr-Mn ${ }^{a}$

\begin{tabular}{|c|c|c|c|c|}
\hline Entry & Substrate & Conversion $[\%]^{[\mathrm{b}]}$ & Yield $[\%]^{[\mathrm{b}]}$ & Selectivity $[\%]^{[\mathrm{b}, \mathrm{c}]}$ \\
\hline 1 & & 79 & 78 & $>99$ \\
\hline 2 & & 63 & 62 & $>99$ \\
\hline 3 & & 64 & 63 & $>99$ \\
\hline 4 & & 67 & 66 & $>99$ \\
\hline 5 & & 74 & 73 & $>99$ \\
\hline 6 & & 60 & 46 & 77 \\
\hline
\end{tabular}

${ }^{a}$ Reaction conditions: alcohol $(0.5 \mathrm{mmol})$, catalyst $(0.3 \mathrm{eq} . \mathrm{Mn})$, anhydrous toluene $(5 \mathrm{~mL})$, under air flow, temperature $110{ }^{\circ} \mathrm{C}, 5 \mathrm{~h} .{ }^{b} \mathrm{Conversion}$, yield and selectivity were established by GC-MS, using dodecane as intern standard. ${ }^{c}$ The selectivity was calculated as the ratio of yield over conversion.

The activity of Pyr- $\mathrm{Mn}_{2}$ was also compared with other manganese catalysts and well-known oxidative reagents. In the same reaction conditions, only $36 \%$ yield was obtained with commercial activated $\mathrm{MnO}_{2}$, supporting the performance of Pyr- $\mathrm{Mn}_{2}$ (Table 5, entries 1 and 6). To afford $89 \%$ yield, 12 equiv of $\mathrm{MnO}_{2}$ and $23 \mathrm{~h}$ of reaction time were needed for Highet and Wildman ${ }^{24}$ (Table 5, entry 7). Son et al. used octahedral molecular sieves (K-OMS-2) in the same reactional conditions and also obtained $90 \%$ yield in benzaldehyde (Table 5, entry 8). Different amorphous $\mathrm{MnO}_{x}$ catalysts were engaged in benzyl alcohol oxidation by $\mathrm{Hu}$ et al., and yields between $17 \%$ and $72 \%$ were reached in $1.5 \mathrm{~h}^{25}$ (Table 5, entry 9). On the contrary, crystalline $\gamma-\mathrm{MnO}_{2}$ showed very low activity for aerobic oxidation of benzyl alcohol (Table 5, entry 10). Shurz et al. supported the highest catalytic activity of amorphous manganese oxides compared to crystalline oxides, as crystalline $\mathrm{MnO}, \mathrm{Mn}_{2} \mathrm{O}_{3}$, and $\mathrm{Mn}_{3} \mathrm{O}_{4}$ did not show any activity. $^{26}$
Chromium-based reagents, ${ }^{27}$ hypervalent iodine reagents such as Dess-Martin Periodinane, ${ }^{28}$ or DMSO-activated reagents $^{29}$ were figured among the most widely used oxidative reagents (Table 5, entries 11-13). Unlike those reagents, Pyr$\mathrm{Mn}_{2}$ can be used in catalytic quantities, while conserving competitive conversions and yields, within a reasonable reaction time and in an acceptable solvent, contrary to CMR solvent like chloroform (Table 5, entry 7 ), dichloromethane (Table 5, entries 11 and 13) or acetonitrile (Table 5, entry 12). Its nontoxic and ecofriendly use contributed to make it an efficient and green system, as much in the catalyst it-self-as in the reaction conditions.

As Pyr- $\mathrm{Mn}_{2}$ showed the best reactivity for alcohol oxidation, we studied the versatility of $\mathrm{Pyr}-\mathrm{Mn}_{2}$ on the aerobic oxidation of other alcohols. Results were reported in Table 6. The activity of Pyr- $\mathrm{Mn}_{2}$ remained quite similar regarding primary (Table 6, entries 1-3), secondary (Table 6, entry 4) and allylic alcohol (Table 6, entry 5). These results prove the generality of 
Table 7. Reusability of Pyr-Mn $\mathrm{Mn}_{2}$ Catalyst in the Oxidative Cleavage of meso-Hydrobenzoin ${ }^{a}$

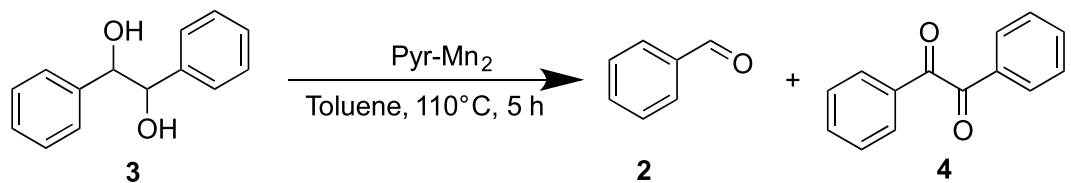

\begin{tabular}{|c|c|c|c|c|c|c|c|c|c|c|c|c|}
\hline \multirow[b]{2}{*}{ entry } & \multirow[b]{2}{*}{ run } & \multicolumn{7}{|c|}{ composition (wt $\% \pm \mathrm{SD}$ ) } & \multirow[b]{2}{*}{$\begin{array}{c}\text { temp } \\
{[\mathrm{h}]}\end{array}$} & \multirow[b]{2}{*}{$\begin{array}{l}\text { conv } \\
{[\%]^{b}}\end{array}$} & \multirow[b]{2}{*}{$2[\%]^{b}$} & \multirow[b]{2}{*}{$4[\%]^{b}$} \\
\hline & & $\mathrm{Mn}$ & $\mathrm{Na}$ & $\mathrm{K}$ & $\mathrm{Mg}$ & $\mathrm{Ca}$ & $\mathrm{Fe}$ & $\mathrm{Al}$ & & & & \\
\hline 1 & no. 1 & $3.0( \pm 0.2)$ & $0.03( \pm 0.02)$ & $0.05( \pm 0.02)$ & $12.7( \pm 0.8)$ & $4.53( \pm 0.7)$ & $2.7( \pm 0.2)$ & $1.2( \pm 0.1)$ & 5 & 100 & 71 & 29 \\
\hline 2 & no. 2 & $2.9( \pm 0.4)$ & $0.1( \pm 0.1)$ & $0.1( \pm 0.1)$ & $12.0( \pm 1.8)$ & $4.2( \pm 0.6)$ & $2.6( \pm 0.4)$ & $1.2( \pm 0.2)$ & 24 & 100 & 72 & 28 \\
\hline $\begin{array}{l}3 \\
4\end{array}$ & no. 3 & $2.7( \pm 0.1)$ & $0.01( \pm 0.01)$ & $0.1( \pm 0.1)$ & $11.3( \pm 0.1)$ & $2.4( \pm 1.7)$ & $2.5( \pm 0.1)$ & $1.1( \pm 0.1)$ & $\begin{array}{r}5 \\
24\end{array}$ & $\begin{array}{l}20 \\
73\end{array}$ & $\begin{array}{l}14 \\
31\end{array}$ & $\begin{array}{r}6 \\
42\end{array}$ \\
\hline
\end{tabular}

${ }^{a}$ Reaction conditions: diol $(0.5 \mathrm{mmol})$, catalyst $(0.3$ eq. $\mathrm{Mn})$, anhydrous toluene $(5 \mathrm{~mL})$, under air flow, $110{ }^{\circ} \mathrm{C}, 5$ h. ${ }^{b} \mathrm{Conversion}$ and yields were established by GC-MS using biphenyl as interne standard.

Table 8. Oxidative Cleavage of 1,2-Diols Catalyzed by Pyr-Mn or Other Mn Polymetallic Catalysts

\begin{tabular}{|c|c|c|c|c|c|c|}
\hline Entry & Catalyst & Oxidant & Solvent & Substrate & $\begin{array}{l}\text { Conversion } \\
{[\%]^{[\mathrm{b}]}}\end{array}$ & $\begin{array}{l}\mathbf{2} \\
{[\%]^{[b]}}\end{array}$ \\
\hline $1^{[\mathrm{a}]}$ & Pyr- $\mathrm{Mn}_{2}$ & $\mathrm{O}_{2}$ & Toluene & & 100 & 71 \\
\hline $2^{[\mathrm{a}]}$ & Pyr- $\mathrm{Mn}_{3}$ & $\mathrm{O}_{2}$ & Toluene & & 100 & 84 \\
\hline $3^{[\mathrm{a}]}$ & Pyr- $\mathrm{Mn}_{3}$ & $\mathrm{O}_{2}$ & Toluene & & 100 & 100 \\
\hline $4^{[a]}$ & Pyr-Mn ${ }_{3}$ & $\mathrm{O}_{2}$ & Toluene & & 100 & $>95$ \\
\hline 5 & EcoMnOx $^{12}$ & $\mathrm{O}_{2}$ & 1-butanol & & 57 & 56 \\
\hline 6 & $\mathrm{Na}-\mathrm{Mn} \mathrm{LMO}^{42}$ & $\mathrm{O}_{2}$ & 1-butanol & & 29 & 15 \\
\hline & & $\mathrm{O}_{2}+\mathrm{NaHCO}_{3}$ & & & 83 & 53 \\
\hline 7 & $\begin{array}{l}{[\mathrm{Mn}(\text { salen })(\mathrm{Py})]} \\
(\mathrm{OAc})^{44}\end{array}$ & $\begin{array}{l}\mathrm{O}_{2}+ \\
\text { salicylaldehyde }\end{array}$ & $\begin{array}{l}{[\mathrm{BMIM}][\mathrm{P}} \\
\left.\mathrm{F}_{6}\right]\end{array}$ & & 100 & 43 \\
\hline 8 & $\begin{array}{l}\left(\mathrm{Ph}_{4} \mathrm{P}\right)[\mathrm{Mn}(\mathrm{opb} \\
\left.\text { a)(py })_{2}\right] \cdot 2 \mathrm{H}_{2} \mathrm{O}^{45}\end{array}$ & $\begin{array}{l}\mathrm{O}_{2}+ \\
\text { pivalaldehyde }\end{array}$ & Acetonitrile & & 100 & 33 \\
\hline
\end{tabular}

${ }^{a}$ Reaction conditions: diol $(0.5 \mathrm{mmol})$, catalyst $(0.3 \mathrm{eq} . \mathrm{Mn})$, anhydrous toluene $(5 \mathrm{~mL})$, under air flow, $110{ }^{\circ} \mathrm{C}, 5 \mathrm{~h} .{ }^{b}$ Conversion and yields were established by GC-MS using biphenyl as intern standard.

the proposed method. It should also be noticed the total selectivity obtained for each case.

Pyr- $\mathrm{Mn}_{2}$ was also tested in the selective oxidation of 5hydroxymethyl-2-furfural (HMF) in 2,5-diformylfuran (DFF). As it derives from the dehydration of carbohydrates such as fructose, glucose, cellulose, and insulin, ${ }^{34-36}$ HMF represents a renewable alternative from fossil-fuel resources. HMF is considered a building block platform for the synthesis of many top-value-added chemicals. ${ }^{37}$ Selective oxidation of the hydroxyl group in aldehyde is of particular interest as DFF finds various applications. ${ }^{38-40} 60 \%$ conversion was reached by using Pyr- $\mathrm{Mn}_{2}$, with $77 \%$ selectivity in DFF (Table 6, entry 6). An IR analysis and a GC-MS analysis of the products obtained after silylation by N,O-bis(trimethylsilyl)trifluoroacetamide revealed that no carboxylic acids were formed. This result proved one more time that no overoxidation occurred using Pyr-Mn catalysts. 
Table 9. Epoxidation of Alkenes with Effluents, in the Presence of $\mathrm{NaHCO}_{3}$ and $\mathrm{H}_{2} \mathrm{O}_{2}{ }^{a}$

\begin{tabular}{|c|c|c|c|c|c|c|}
\hline Entry & Substrate & Product & Solvent & $\begin{array}{l}\text { Conversion } \\
{[\%]^{[b]}}\end{array}$ & $\begin{array}{l}\text { Yield } \\
{[\%]^{[\mathrm{b}]}}\end{array}$ & $\begin{array}{l}\text { Selectivity } \\
{[\%]^{[\mathrm{b}, \mathrm{c}]}}\end{array}$ \\
\hline 1 & & & $t$-BuOH & 91 & 91 & $>99$ \\
\hline 2 & & & $t-\mathrm{BuOH}$ & 81 & 81 & $>99$ \\
\hline 3 & & & $t-\mathrm{BuOH}$ & 86 & 86 & $>99$ \\
\hline 4 & & & $t-\mathrm{BuOH}$ & 49 & 41 & 84 \\
\hline 5 & & & $\begin{array}{l}t-\mathrm{BuOH}+ \\
5 \text { eq. Acetone }\end{array}$ & $>99$ & 64 & 64 \\
\hline 6 & & & Acetone & $>99$ & 99 & 99 \\
\hline 7 & & & Acetone & $>99$ & 99 & 99 \\
\hline 8 & & & Acetone & $>99$ & 84 & 83 \\
\hline 9 & & & Acetone & $>99$ & 89 & 88 \\
\hline 10 & & & Acetone & $>99$ & 77 & 76 \\
\hline 11 & & & Acetone & $>99$ & 82 & 80 \\
\hline 12 & & & Acetone & 54 & 38 & 70 \\
\hline
\end{tabular}

${ }^{a}$ Reaction conditions: alkene $(0.18 \mathrm{mmol})$, effluent $(0.00006$ eq. $\mathrm{Mn}), \mathrm{NaHCO}_{3}(0.88 \mathrm{mmol}), \mathrm{H}_{2} \mathrm{O}_{2}(1.75 \mathrm{mmol}), t-\mathrm{BuOH} / \mathrm{acetone}(2.6 \mathrm{~mL})$, under air, $30^{\circ} \mathrm{C}, 2 \mathrm{~h} .{ }^{b}$ Conversion, yield and selectivity were established by GC-MS using dodecane as intern standard. ${ }^{c}$ The selectivity was calculated as the ratio of yield over conversion. 
Our approach presents several advantages compared to the current processes. First of all, the reaction does not need high pressure as it is performed under atmospheric conditions. Moreover, an air flow succeeds in regenerating the catalysts so pure oxygen flow or oxygen atmosphere are avoided. The quantity of $\mathrm{Mn}$ involved into the oxidation reaction is far below the necessary quantities reported into the literature. Last but not least, our synthetic process meets European Performance Standards as the remaining manganese concentration into the effluents after treatment is below $0.1 \mathrm{ppm}$ (Table S6). The effluent can be discharged into the environment, without any health risks for nearby population nor pollution of ecosystems in surrounding areas.

Experimental Studies of Effluents as a Promoter of the Oxidative Cleavages. Oxidative cleavage of 1,2-diols is one of the paramount oxidation reactions. Whereas the stoichiometric oxidants such as periodate, tetra-acetate lead and ozonolysis lead to toxicity problems and lack of selectivity, catalytic systems are often based on expensive, precious, nonrecyclable or toxic transition metals (Re, Mo, W, Os, and Co) ${ }^{41}$ In this context, $\mathrm{Mn}^{\mathrm{IV}}$ catalysts are a real opportunity. They allow the development of innocuous, selective and costeffective systems.

Recently, our group has developed two original methods for the aerobic oxidative cleavage of 1,2-diols with polymetallic catalysts prepared from $\mathrm{Mn}$ hyperaccumulating plants. ${ }^{12,42} \mathrm{We}$ wished to apply our new $\mathrm{Pyr}-\mathrm{Mn}_{2}$ catalyst derived from pyrite quarrying in oxidative cleavage reactions, to show the compatibility of the catalyst with different conditions and demonstrate its values as powerful synthetic tools.

meso-Hydrobenzoin was chosen as a model for the oxidative cleavage of 1,2-diols by Pyr- $\mathrm{Mn}_{2}$. As for alcohol oxidation, the oxidative cleavage can be performed under mild conditions. Air atmosphere was sufficient to promote the reaction: no pressure or no atmosphere of $\mathrm{O}_{2}$ was required. Conversion of $100 \%$ was obtained with $71 \%$ yield in benzaldehyde after $5 \mathrm{~h}$ reaction (Table 7 , entry 1 ). The remaining $29 \%$ were assigned to diphenylethanedione. Benzoin was not observed. IR spectra of the crude product also attested that no carboxylic acids were formed during the reaction, contrary to the mixture obtained by Mecozzi et al. ${ }^{43}$ What is more, when the diphenylethanedione was engaged in the presence of the catalyst in the same conditions, no cleavage occurred, even after $24 \mathrm{~h}$. This experiment proves that the diphenylethanedione was not an intermediate product of the cleavage to benzaldehyde. Thus, two types of oxidation proceeded simultaneously: the mild oxidation of meso-hydrobenzoin into diketone as well as the oxidative cleavage into benzaldehyde.

In order to study the recycling of Pyr- $\mathrm{Mn}_{2}$, the catalyst was reused for three runs. After reaction, $\mathrm{Pyr}-\mathrm{Mn}_{2}$ was separated by filtration and washed three times with ethyl acetate and three times with ethanol before being dried in an oven at $140{ }^{\circ} \mathrm{C}$ for $24 \mathrm{~h}$. The recovered catalyst was then reapplied in the oxidative cleavage of meso-hydrobenzoin. As summarized in Table 7, the mineral composition remained virtually the same even after three runs. The conversion and yields were unchanged in the second run, even by letting the reaction proceeding for $24 \mathrm{~h}$ (Table 7 , entry 2 ). However, the reactivity of Pyr- $\mathrm{Mn}_{2}$ decreased when engaged for the third time in the cleavage of meso-hydrobenzoin (Table 7, entries 3 and 4). The conversion increased from only $20 \%$ after $5 \mathrm{~h}$ to $73 \%$ in $24 \mathrm{~h}$.

These results prompted us to look for a new catalyst able to promote preferentially the reaction toward the oxidative cleavage of 1,2-diols. We turned toward $\mathrm{Pyr}-\mathrm{Mn}_{3}$, whose formation at higher $\mathrm{pH}$ was expected to facilitate the oxidation of $\mathrm{Mn}^{\mathrm{II}}$ into $\mathrm{Mn}^{\mathrm{IV}}$.

Benzaldehyde was formed with higher yields with $\mathrm{Pyr}-\mathrm{Mn}_{3}$ for the cleavage of meso-hydroxybenzoin (Table 8, entry 2). The cleavage of 1-phenylethane-1,2-diol is of particular interest. Yield of $100 \%$ was reached with $\mathrm{Pyr}-\mathrm{Mn}_{3}$ (Table 8, entry 3) whereas many Mn-catalysts described in the literature do not work in these conditions. For example, $\mathrm{Na}-\mathrm{Mn} \mathrm{LMO}$ needed the presence of $\mathrm{NaHCO}_{3}$ to reach 53\% conversion (Table 8, entry 6). With EcoMnOx, the cleavage of benzylicaliphatic 1,2-diol required $24 \mathrm{~h}$ to obtain $57 \%$ of conversion (Table 8, entry 5). It should be mentioned that no benzaldehyde was formed when $\mathrm{Pyr}-\mathrm{Mn}_{2}$ was engaged with 1-phenylethane-1,2-diol. Finally, the methodology can be extended to the cleavage of $\alpha$-hydroxyacid, as illustrated with the example of mandelic acid (Table 8, entry 4), for which more than $95 \%$ yield was obtained.

Studying the Catalytic Behavior of Manganese-Based Catalysts for the Epoxidation of Alkenes. The functionalization of alkenes to furnish epoxides in green and sustainable conditions is a motivating challenge. Indeed classical processes, involving organic peroxides or percarboxylic acids such as $m$ chloroperoxybenzoic acid ( $m$-CPBA), ${ }^{46}$ are questionable as regards safety considerations and the large production of wastes. Ideally, ecofriendly oxidants such as $\mathrm{H}_{2} \mathrm{O}_{2}$ in combination with $\mathrm{Mn}$ or $\mathrm{Fe}$ constitute effective catalysts for epoxidation. Recently, our group has reported the first $\mathrm{Mn}$ biosourced catalysts (Eco-Mn) for the epoxidation of relatively reactive olefins. ${ }^{11}$ Starting from the manganese-hyperaccumulating plant Grevillea exul subsp. rubiginosa, we prepared a heterogeneous Eco-Mn catalyst, by incorporation of biosourced polymetallic complexes into montmorillonite K10. The supported Eco-Mn catalyst gave much higher yields of epoxides than previously described Mn-derived heterogeneous catalysts. ${ }^{11}$ However, the process required the preparation of intermediary polymetallic chloride catalysts. Active Eco-Mn were prepared via the sequence thermic treatment of natural resource (leaves)/activation by $\mathrm{HCl}$ /addition of sodium carbonate and oxidation.

It is clear that the possibility of a direct preparation of active Mn catalysts would be much more efficient and ecofriendlier than the synthesis of active Eco-Mn. In order to explore this opportunity, we investigated the direct transformation of effluents into active oxidant catalyst. Unlike Burgess et al., the epoxidation reaction by mixing hydrogen peroxide and aqueous sodium hydrogen carbonate in DMF can be catalyzed by $\mathrm{Mn}^{\mathrm{II}}$ salts in a green solvent instead of $\mathrm{DMF}{ }^{47}$ The formation of a manganese peroxycarbonate complex, which mimics the Mn-catalase, is one of the supposed formulated mechanism. ${ }^{48}$ In that purpose, effluents, as a source of $\mathrm{Mn}^{\mathrm{II}}$ salt (0.00006 eq. $\mathrm{Mn})$, was stirred with $\mathrm{NaHCO}_{3}$ (5 equiv) and alkene ( 1 equiv) in $t$ - $\mathrm{BuOH}$. After $10 \mathrm{~min}, \mathrm{H}_{2} \mathrm{O}_{2}$ (10 equiv) was added and then the mixture was stirred during $2 \mathrm{~h}$ at 30 ${ }^{\circ} \mathrm{C}$. After extraction, the expected epoxide was analyzed by GC-MS. Results are reported in Table 9.

High conversions were obtained with a large variety of alkenes as well as terminal or cyclic substrates with only 0.00006 equiv of $\mathrm{Mn} .100 \%$ selectivity was reached with styrene, cyclooctene, and cyclohexene (Table 9, entries 1-3) in $t-\mathrm{BuOH}$, an ecofriendly solvent. For the less reactive substrates, high conversions were obtained in $t$ - $\mathrm{BuOH}$ with 5 eq. acetone or pure acetone. Total conversion was reached for 
tri- or disubstituted alkenes. The double epoxidation of limonene totally occurred (Table 9, entries 5 and 6), while it was predominant for cyclooctadiene with $83 \%$ of selectivity for the diepoxides (Table 9, entry 8). As a comparison, only monoepoxides of limonene was obtained with Eco-Mn. ${ }^{11}$ Interestingly, the epoxide of $\alpha$-pinene (Table 9, entry 7), which is unstable, was obtained in a quantitative yield. This yield is remarkable and can be advantageously compared with the known systems: $59 \%$ yield obtained by Burgess et al. ${ }^{47}$ and $75 \%$ with Eco-Mn in DMF. ${ }^{11}$ The epoxides from terpenes are attractive for industrial use as biorenewable substrates. For example, Thomas et al. have reported the alternating copolymerization of $\alpha$-pinenoxide and glutaric anhydride to build fully biodegradable copolymer. ${ }^{49}$ Limonene oxide has become an excellent comonomer for the preparation of polyester, whereas limonene dioxide can replace the epichlorhydrin. The epoxide of linalool rearranged into cyclized products. The six membered ring was preferentially obtained, with $88 \%$ of selectivity (Table 9 , entry 9 ). $76 \%$ selectivity was finally reached for nopol (Table 9, entry 10).

Epoxidation is one of the most important functionalization reactions of the $\mathrm{C}=\mathrm{C}$ bond in order to improve the oxidative stability of unsaturated fatty acids. Epoxidized vegetable oils are used as biolubricants and intermediate key molecules.

Oleic acid is a conventional model compound for epoxidation. The epoxidation of oleic acid (Table 9, entry 11) afforded the desired product with high yield, indicating the efficiency of the process. A ratio of $75 / 25$ of epoxides was probably due to the isomerization of the $\mathrm{C}=\mathrm{C}$ double bond before oxidation. A small amount of ketal derived from dihydroxy acid was observed (18\%).

Finally, we applied this system into the epoxidation of one monosubstituted alkene, which is challenging substrate (Table 9 , entry 12). While the cleavage of allylic moiety was observed (14\%), the most product obtained was the expected epoxide (38\%).

\section{CONCLUSION}

In conclusion, we have exploited the effluent waste from pyrite quarries and inorganic chemicals by turning these wastes into valuable resources. The characterization of obtained materials exhibited distinctive mineral composition, morphology and structure for promoting oxidation transformations. They are ecofriendly and innocuous catalysts, which proved to be highly efficient in alcohol oxidations, oxidative cleavages, and epoxidations. Good to excellent selectivities and yields were obtained under mild reaction conditions, simple operations, very low catalyst loading, and good substrate scope. The catalysts are compatible with a wide range of functional groups, making them highly competitive with conventional oxidative catalysts and reagents. Finally, this study encourages the development of recycling technologies, which aims at exploring breakthrough solutions for the development of new ecomaterials and processes within the context of sustainable chemistry.

\section{ASSOCIATED CONTENT}

\section{Supporting Information}

The Supporting Information is available free of chargeat

DOI: $10.1021 /$ acssusche-meng.8b06582.
Evolution of catalyst mineral composition as a function of the $\mathrm{pH}$ of precipitation; Mn 2p XPS spectra of Pyr$\mathrm{Mn}$; HRTEM image of commercial activated $\mathrm{MnO}_{2} ; \mathrm{N}_{2}$ adsorption-desorption isotherm of Pyr- $\mathrm{Mn}_{1}, \mathrm{Pyr}-\mathrm{Mn}_{2}$, and commercial activated $\mathrm{MnO}_{2}$ and pore size distribution of the corresponding samples; STEM-EDX mapping of $\mathrm{Pyr}-\mathrm{Mn}_{1}$; study of the mineral composition of effluents after filtration (PDF)

\section{AUTHOR INFORMATION}

\section{Corresponding Author}

*E-mail: claude.grison@cnrs.fr.

ORCID 1

Claude Grison: 0000-0002-2687-1520

Notes

The authors declare no competing financial interest.

\section{ACKNOWLEDGMENTS}

The authors would like to thank CNRS and ENS for financial support. Colas Centre Ouest and GBN are acknowledged for the effluents. Plateforme Microscopie Electronique et Analytique of University of Montpellier has our thanks for TEM and HRTEM analyses.

\section{REFERENCES}

(1) Ecology of Industrial Pollution, 1st ed.; Batty, L. C., Hallberg, K. B., Eds.; Cambridge University Press: Cambridge; New York, 2010.

(2) Candidate List of substances of very high concern for Authorisation - ECHA https://echa.europa.eu/candidate-list-table (accessed Jun 4, 2018).

(3) Bricker, T. M.; Ghanotakis, D. F. Introduction to Oxygen Evolution and the Oxygen-Evolving Complex. In Oxygenic Photosynthesis: The Light Reactions; Advances in Photosynthesis and Respiration; Springer: Dordrecht, 1996; pp 113-136.

(4) Pascal, P. In Nouveau traité de chimie minérale; Masson: Paris, 1960; Vol. XVI, p 773.

(5) Anastas, P.; Warner, J. Green Chemistry: Theory and Practice; Oxford University Press: Oxford; New York, 2000.

(6) Gerber, G. B.; Léonard, A.; Hantson, P. Carcinogenicity, Mutagenicity and Teratogenicity of Manganese Compounds. Critical Reviews in Oncology/Hematology 2002, 42 (1), 25-34.

(7) 24 - Manganese, Technetium and Rhenium. In Chemistry of the Elements, Second edition; Butterworth-Heinemann: Oxford, 1997; pp 1040-1069.

(8) Cahiez, G.; Alami, M.; Taylor, R. J. K.; Reid, M.; Foot, J. S. Manganese Dioxide. In Encyclopedia of Reagents for Organic Synthesis; John Wiley \& Sons, Ltd: Chichester, 2004.

(9) Escande, V.; Velati, A.; Garel, C.; Renard, B.-L.; Petit, E.; Grison, C. Phytoextracted Mining Wastes for Ecocatalysis: Eco-Mn®, an Efficient and Eco-Friendly Plant-Based Catalyst for Reductive Amination of Ketones. Green Chem. 2015, 17 (4), 2188-2199.

(10) Escande, V.; Renard, B.-L.; Grison, C. Lewis Acid Catalysis and Green Oxidations: Sequential Tandem Oxidation Processes Induced by Mn-Hyperaccumulating Plants. Environ. Sci. Pollut. Res. 2015, 22 (8), 5633-5652.

(11) Escande, V.; Petit, E.; Garoux, L.; Boulanger, C.; Grison, C. Switchable Alkene Epoxidation/Oxidative Cleavage with $\mathrm{H}_{2} \mathrm{O}_{2}$ $/ \mathrm{NaHCO}_{3}$ : Efficient Heterogeneous Catalysis Derived from Biosourced Eco-Mn. ACS Sustainable Chem. Eng. 2015, 3 (11), 2704-2715.

(12) Escande, V.; Lam, C. H.; Grison, C.; Anastas, P. T. EcoMnOx, a Biosourced Catalyst for Selective Aerobic Oxidative Cleavage of Activated 1,2-Diols. ACS Sustainable Chem. Eng. 2017, 5 (4), 32143222. 
(13) Charlot, G. Les réactions chimiques en solution; l'analyse qualitative minérale; Masson et Cie: Paris, 1969.

(14) Neaţu, F.; Petrea, N.; Petre, R.; Somoghi, V.; Florea, M.; Parvulescu, V. I. Oxidation of 5-Hydroxymethyl Furfural to 2,5Diformylfuran in Aqueous Media over Heterogeneous Manganese Based Catalysts. Catal. Today 2016, 278, 66-73.

(15) Nie, J.; Liu, H. Efficient Aerobic Oxidation of 5Hydroxymethylfurfural to 2,5-Diformylfuran on Manganese Oxide Catalysts. J. Catal. 2014, 316, 57-66.

(16) Carver, J. C.; Schweitzer, G. K.; Carlson, T. A. Use of X-Ray Photoelectron Spectroscopy to Study Bonding in $\mathrm{Cr}, \mathrm{Mn}, \mathrm{Fe}$, and Co Compounds. J. Chem. Phys. 1972, 57 (2), 973-982.

(17) Aoki, A. X-Ray Photoelectron Spectroscopic Studies on ZnS: MnF2 Phosphors. Jpn. J. Appl. Phys. 1976, 15, 305.

(18) Biesinger, M. C.; Payne, B. P.; Grosvenor, A. P.; Lau, L. W. M.; Gerson, A. R.; Smart, R. S. C. Resolving Surface Chemical States in XPS Analysis of First Row Transition Metals, Oxides and Hydroxides: Cr, Mn, Fe, Co and Ni. Appl. Surf. Sci. 2011, 257 (7), 2717-2730.

(19) Nesbitt, H. W.; Banerjee, D. Interpretation of XPS Mn(2p) Spectra of Mn Oxyhydroxides and Constraints on the Mechanism of MnO 2 Precipitation. Am. Mineral. 1998, 83 (3-4), 305-315.

(20) Portehault, D.; Cassaignon, S.; Nassif, N.; Baudrin, E.; Jolivet, J.-P. A Core-Corona Hierarchical Manganese Oxide and Its Formation by an Aqueous Soft Chemistry Mechanism. Angew. Chem., Int. Ed. 2008, 47 (34), 6441-6444.

(21) Ching, S.; Kriz, D. A.; Luthy, K. M.; Njagi, E. C.; Suib, S. L. Self-Assembly of Manganese Oxide Nanoparticles and Hollow Spheres. Catalytic Activity in Carbon Monoxide Oxidation. Chem. Commun. 2011, 47 (29), 8286-8288.

(22) Luo, K.; Zhao, S.-X.; Wang, Y.-F.; Zhao, S.-J.; Zhang, X.-H. Synthesis of Petal-like $\delta$-MnO2 and Its Catalytic Ozonation Performance. New J. Chem. 2018, 42 (9), 6770-6777.

(23) Augustin, M.; Fenske, D.; Bardenhagen, I.; Westphal, A.; Knipper, M.; Plaggenborg, T.; Kolny-Olesiak, J.; Parisi, J. Manganese Oxide Phases and Morphologies: A Study on Calcination Temperature and Atmospheric Dependence. Beilstein J. Nanotechnol. 2015, 6, 47-59.

(24) Highet, R. J.; Wildman, W. C. Solid Manganese Dioxide as an Oxidizing Agent. J. Am. Chem. Soc. 1955, 77 (16), 4399-4401.

(25) Hu, J.; Sun, K.; He, D.; Xu, B. Amorphous Manganese Oxide for Catalytic Aerobic Oxidation of Benzyl Alcohol. Chinese Journal of Catalysis 2007, 28 (12), 1025-1027.

(26) Schurz, F.; Bauchert, J. M.; Merker, T.; Schleid, T.; Hasse, H.; Gläser, R. Octahedral Molecular Sieves of the Type K-OMS-2 with Different Particle Sizes and Morphologies: Impact on the Catalytic Properties in the Aerobic Partial Oxidation of Benzyl Alcohol. Appl. Catal., A 2009, 355 (1), 42-49.

(27) Warrener, R. N.; Lee, T. S.; Russell, R. A.; Paddon-Row, M. N. A Comparative Study of Jones's, Collins's and Corey's Reagents in the Chromium(VI) Oxidation of an Epimeric Pair of Allylic Alcohols in the Benzo-Fused Norbornen-5-Ol Series. Aust. J. Chem. 1978, 31 (5), $1113-1127$.

(28) Dess, D. B.; Martin, J. C. Readily Accessible 12-I-5 Oxidant for the Conversion of Primary and Secondary Alcohols to Aldehydes and Ketones. J. Org. Chem. 1983, 48 (22), 4155-4156.

(29) Mancuso, A. J.; Swern, D. Activated Dimethyl Sulfoxide: Useful Reagents for Synthesis. Synthesis 1981, 1981 (3), 165-185.

(30) Son, Y.-C.; Makwana, V. D.; Howell, A. R.; Suib, S. L. Efficient, Catalytic, Aerobic Oxidation of Alcohols with Octahedral Molecular Sieves. Angew. Chem., Int. Ed. 2001, 40 (22), 4280-4283.

(31) Collins, J. C.; Hess, W. W.; Frank, F. J. DipyridineChromium(VI) Oxide Oxidation of Alcohols in Dichloromethane. Tetrahedron Lett. 1968, 9 (30), 3363-3366.

(32) Dess, D. B.; Martin, J. C. A Useful 12-I-5 Triacetoxyperiodinane (the Dess-Martin Periodinane) for the Selective Oxidation of Primary or Secondary Alcohols and a Variety of Related 12-I-5 Species. J. Am. Chem. Soc. 1991, 113 (19), 7277-7287.
(33) Omura, K.; Swern, D. Oxidation of Alcohols by "Activated" Dimethyl Sulfoxide. a Preparative, Steric and Mechanistic Study. Tetrahedron 1978, 34 (11), 1651-1660.

(34) Lewkowski, J. Synthesis, Chemistry and Applications of 5Hydroxymethyl-Furfural and Its Derivatives. ARKIVOC 2005, 2001 (1), 17-54.

(35) Kuster, B. F. M. 5-Hydroxymethylfurfural (HMF). A Review Focussing on its Manufacture. Starch - Stärke 1990, 42 (8), 314-321.

(36) Chheda, J. N.; Román-Leshkov, Y.; Dumesic, J. A. Production of 5-Hydroxymethylfurfural and Furfural by Dehydration of BiomassDerived Mono- and Poly-Saccharides. Green Chem. 2007, 9 (4), 342 350.

(37) Rosatella, A. A.; Simeonov, S. P.; Frade, R. F. M.; Afonso, C. A. M. 5-Hydroxymethylfurfural (HMF) as a Building Block Platform: Biological Properties, Synthesis and Synthetic Applications. Green Chem. 2011, 13 (4), 754-793.

(38) Gandini, A. Furans in Polymer Chemistry. Prog. Polym. Sci. 1997, 22 (6), 1203-1379.

(39) Hopkins, K. T.; Wilson, W. D.; Bender, B. C.; McCurdy, D. R.; Hall, J. E.; Tidwell, R. R.; Kumar, A.; Bajic, M.; Boykin, D. W. Extended Aromatic Furan Amidino Derivatives as Anti- Pneumocystis Carinii Agents. J. Med. Chem. 1998, 41 (20), 3872-3878.

(40) Ma, J.; Du, Z.; Xu, J.; Chu, Q.; Pang, Y. Efficient Aerobic Oxidation of 5-Hydroxymethylfurfural to 2,5-Diformylfuran, and Synthesis of a Fluorescent Material. ChemSusChem 2011, 4 (1), $51-54$.

(41) Kühn, F. E.; Fischer, R. W.; Herrmann, W. A.; Weskamp, T. Oxidative Cleavage of Olefins. In Transition Metals for Organic Synthesis; Wiley-Blackwell, 2008; pp 427-436.

(42) Escande, V.; Lam, C. H.; Coish, P.; Anastas, P. T. Heterogeneous Sodium-Manganese Oxide Catalyzed Aerobic Oxidative Cleavage of 1,2-Diols. Angew. Chem., Int. Ed. 2017, 56 (32), 9561-9565.

(43) Mecozzi, F.; Dong, J. J.; Saisaha, P.; Browne, W. R. Oxidation of Vicinal Diols to $\alpha$-Hydroxy Ketones with $\mathrm{H} 2 \mathrm{O} 2$ and a Simple Manganese Catalyst. Eur. J. Org. Chem. 2017, 2017 (46), 6919-6925.

(44) Riaño, S.; Fernández, D.; Fadini, L. Oxidative Cleavage of VicDiols Catalyzed by Manganese (III) Complexes in Ionic Liquids. Catal. Commun. 2008, 9 (6), 1282-1285.

(45) Barroso, S.; Blay, G.; Fernández, I.; Pedro, J. R.; Ruiz-García, R.; Pardo, E.; Lloret, F.; Muñoz, M. C. Chemistry and Reactivity of Mononuclear Manganese Oxamate Complexes: Oxidative CarbonCarbon Bond Cleavage of Vic-Diols by Dioxygen and Aldehydes Catalyzed by a Trans-Dipyridine Manganese(III) Complex with a Tetradentate o-Phenylenedioxamate Ligand. J. Mol. Catal. A: Chem. 2006, 243 (2), 214-220.

(46) Sienel, G.; Rieth, R.; Rowbottom, K. T. Epoxides. In Ullmann's Encyclopedia of Industrial Chemistry; American Cancer Society, 2000.

(47) Lane, B. S.; Vogt, M.; DeRose, V. J.; Burgess, K. ManganeseCatalyzed Epoxidations of Alkenes in Bicarbonate Solutions. J. Am. Chem. Soc. 2002, 124 (40), 11946-11954.

(48) Saisaha, P.; de Boer, J. W.; Browne, W. R. Mechanisms in Manganese Catalysed Oxidation of Alkenes with $\mathrm{H} 2 \mathrm{O} 2$. Chem. Soc. Rev. 2013, 42 (5), 2059-2074.

(49) Robert, C.; de Montigny, F.; Thomas, C. M. Tandem Synthesis of Alternating Polyesters from Renewable Resources. Nat. Commun. 2011, 2, 586. 